\title{
Nesting, Protective and Foraging Behavior of Oecophylla smaragdina (Weaver Ants) in Anand, Gujarat
}

\author{
Divyangi Patel, Nikunj Bhatt ${ }^{*}$ \\ Vitthalbhai Patel \& Rajratna P.T. Patel Science College, Vallabh Vidyanagar, 388120, India
}

Received April 13, 2020; Revised May 11, 2020; Accepted June 16, 2020

Copyright@2020 by authors, all rights reserved. Authors agree that this article remains permanently open access under the terms of the Creative Commons Attribution License 4.0 International License

\begin{abstract}
The ant species of genus Oecophylla shows unexpected social behavior (eusociality). Our present study reveals the development of nests, protective behavior and foraging behavior by $O$. smaragdina. According to the studies, a single nest has different types of castes that help to build a nest. We studied several nests during summer $\left(>42^{\circ} \mathrm{C}\right)$. The castes: workers, drones and queens constitute the nest. The queen during their nuptial flight, mate with the male and comes back to the nest for laying eggs. The worker ants squeeze the fluid (lac/silk) from unfertilized eggs of drone larva at the periphery for sealing the leaves. In our study, we have also focused on possessiveness of ants towards their colony mates. It has been observed that once their colony is disturbed they begin to migrate to other places of same or different tree to prepare a new shelter for them. The queens in the colony feed up on insects captured by workers. Ants obtain their food with the help of other nest mates by a specialized activity known as "foraging". It is well adapted by ants and it is achieved by special group called foragers. Together with food, they generally march towards their own nest rather than moving to others nest conforming nest specificity. In this study, we have considered O.smaragdina. From the study, we have concluded that O.smaragdina show eusociality for nest building, protecting and foraging behavior.
\end{abstract}

Keywords Oecophylla smaragdina, Eusociality, Nest Mates, Colony, Nesting Behavior, Protective Behavior and Foraging Behavior

\section{Introduction}

Ants are adapted to live predominantly in any environment in which they reside. During Mesozoic era, they appeared and evolved from a worm like insect with primitive wings adapted for flight, since that day they have been present till now showing the most complex behaviour [7]. Additionally another instance of evolution made the ants to live mutualistically in large colonies that explain eusociality [7]. The ants belong to order hymenoptera and family formicidae. There are specifically two ant species of genus Oecophylla that prevail social behaviour. Oecophylla ant larvae are commercial products from which oil can be extracted, can be used as edible product, etc. in several Asian countries [8]. Two species of Oecophylla, viz.O. longinoda that are found typically in equatorial Africa, while $O$. smaragdina found in Sri Lanka and India through Indo-China and Southern China to the Indo-malayan region, northern Australia and Malaysia [15]. The weaver ant Oecophylla longinoda and Oecophylla smaragdina live in a society where work is well allocated within a population in highly precise manner [14]. Oecophylla smaragdina (weaver ants) are well known for producing extremely complex nests [18]. These ants generally build their nests by weaving the leaves of trees that are in the vicinity to each other by forming closed circuit structure with many diverse compartments. Ants are ecologically varied organisms which have a similar body shape [2]. The ants are the organism that just varies in colour and size throughout the world. Generally, a single mated queen (haplometrosis) from the nest is responsible for colony reproduction in ants as well as other new nests nevertheless occasionally many cooperating queens are involved (pleometrosis). Pleometrosis is a phenomenon that facilitate flourishing colony establishment under unfavorable circumstances, but it is not inevitable [4]. They are generally more abundant in summer when the temperature is more than $39^{\circ} \mathrm{C}$. Mostly their food is carbohydrate rich towards which they are attracted to. According to the type of weather, there is continuous activity outside the nest constantly in the wet tropics or in a 
diurnal pattern in the drier part of recurring climates. Normally, in wet season colonies tend to multiply throughout the region where they are found and then contract to smaller number and bigger nests during the desiccated months of winter. These ant species can dictate up to 50 to $75 \%$ of the trees at a certain site depending on time of year [17]. There are some ants which feed on other insects like weaver ants. Oecophylla smaragdina are well known for building nests on leaves of the trees. This activity of building nest is performed by all the workers of the nest by division of labor. The workers are dimorphic, namely, major and minor forms, where the major workers are involved in the foraging and nest construction activity, and the minor workers remain in and around the nest, where they are involved in the maintenance of the colony and caring of the queen as well [6]. One to three days later the first worker emerges through the nest and it is opened through a gap and furthermore the exterior activity starts [15]. As soon as the queen dies the workers activates their ovaries to produce a last set of male brood prior to the colony shrinks as worker numbers reduce over the subsequent months [15]. There are a number of tasks for workers in the colony depending on the species, workers are dedicated to brood care (nursing), maintenance of nest, foraging as well as colony defense [19]. During the formation of new nest, individual workers explore for appropriate bunch of leaves, which they grab with their mandibles and endeavor to draw together. Other workers are attracted to the site, presumably by the success of first workers, join the efforts [11]. Weaver ants use silk to collectively fix the leaves to construct their arboreal nests, but fascinatingly, silk is only produced by labial glands of larvae, the workers generally hold the larvae in their jaws and use them as silk dispensers to weave the nest [3]. The ant shows active antennation of individuals when a stranger is recognized that seeks to enter the nest though the nest as well as the colony is highly complicated in structure. Such behavior can enhance the possessiveness towards colony mates and also avoid interspecific mating behavior [17].The ant species have sharp recognition for the colony and non-colony mates. They determine them as dear enemy and nasty neighbors depending upon the behavior of weaver ant workers toward intruders from both neighboring and distant colonies [16]. Different ant species have different dietary requirements, and consequently this must be considered during ant bait formulation. Foraging activities of ants are of two types, to be precise daily foraging activity and seasonal foraging activity. The daily foraging pattern is the daily routine of ants within 24 hours such as foragers seeking foods outside their nests and brings back the food to their colonies, whereas the seasonal foraging pattern reflects the response to seasonal variation like winter and summer. Different biotic and abiotic factors control both daily and seasonal foraging activity in ants. Biotic factors such as natural enemies, inter-specific competition, and reserve availability affect both daily and seasonal activities of many ant species while abiotic factors such as temperature and relative humidity are major factors that affect the foraging patterns among different species of ants. By studying daily foraging patterns, ants can be categorized as active during daytime (diurnal), nighttime (nocturnal), or active during both dusk and dawn (crepuscular) [12]. There are two main phases of foraging: an initial is exploration for food, while later is carrying that food back to the nest [10]. The Oecophylla smaragdina are the ants that forage more during day time as they socialize more when the amount of light as well as heat is at maximum verge. Humidity influences the response of outgoing foragers to returning foragers as wells as foraging up to certain extent [5]. It is possible that humidity affects the behavior of returning foragers in some way that increases the extent to which returning foragers stimulate those waiting inside the nest entrance. Some ants prefer food that is proteinaceous in nature. The Crematogaster ants are basically seen almost everywhere in world. Gujarat has four native species of Crematogaster; viz. Crematogaster aberrans, Crematogaster contemta, Crematogaster rothneyi and Crematogaster subnuda [1]. These ants generally eat the substances that have good protein content such as feathers, nails and dead skin of humans (experimental). The Oecophylla smaragdina are omnivorous. The study revealed about Oecophylla smaragdina that they highly prefer tuna (fish), chicken skin and milk powder [12]. During the process of foraging, the nest mates help each other (foragers) to bring the food into the nest. This whole behavior of weaver ants is same as other species of hymenoptera. This depicts the collective effort of all the foragers of the colony.

\section{Objectives}

1. The main aspect for the present study was planned to observe, analyze and recognize the nest building behavior of weaver ants (Oecophylla smaragdina) particularly during the months of June, 2019 and July, 2019 (warm season) because the prevalence of these ants is at highest verge during this time.

2. We also focused on the protective behavior of ants during nest disturbance, where the ants have rushed to other place within the same colony to build another nest for the rest of the nest mates and especially for queens. Nest disturbance is influenced by various other factors naturally but here we will be disturbing it only to know the way indulge to save their colony or nest mates.

3. Foraging in invertebrates helps the other nest mates to have food without peeping out in the external environment. Additionally we also observed the 
pattern of foraging among the Oecophylla smaragdina for the survival of their colony mates during their life cycle and specifically for providing the food to the queen to produce next generation.

\section{Methodology}

\section{1) Nesting Behavior}

The four nests of Oecophylla smaragdina from the colonies were observed for 5 hours a day from 11:00 am to 4:00 pm in order to outline the nesting behavior in the botanical garden of Vitthalbhai Patel \& Rajratna P.T.Patel Science College, Vallabh Vidyanagar, where human interference was least so that natural habitat can be maintained and botanical garden of Ayurvedic college from A. D. Patel Institute of Technology campus, New Vallabh Vidya Nagar. We observed these nests with the help of Olympus (8x) binocular and photographs were also taken by Nikon 3500 DSLR camera.

\section{2) Protective Behavior}

To study and report the novel protective behavior amongst Oecophylla smaragdina, nests were collected from trees of the botanical garden of Vitthalbhai Patel \&Rajratna P. T. Patel Science College, Vallabh Vidya Nagar and New Vallabh Vidya Nagar. The intact nests were extracted using a long hooked stick and brought to the unsoiled place. We kept them on a clean sheet of paper. Then we dissected the nest using forceps and scissors. The queens were easily available in the nest as that was the most favorable season for mating as the temperature as well as the humidity is extremely high (June 2019 and July 2019). The minor and major workers were segregated and the larvae were also observed [13]. The larvae were also collected in separate bottle. The queen was also taken in another specimen bottle. Photographs of queen, larvae, worker (minor and major) were clicked.

\section{3) Foraging Behavior}

Foraging behavior in Oecophylla smaragdina was observed without any prior fix meal or any type of food preferences. It was reported directly near by the nests with in the colony itself that how and what type of food these species carry to their respective nests to feed the other members of the nests including queens.

\section{Result}




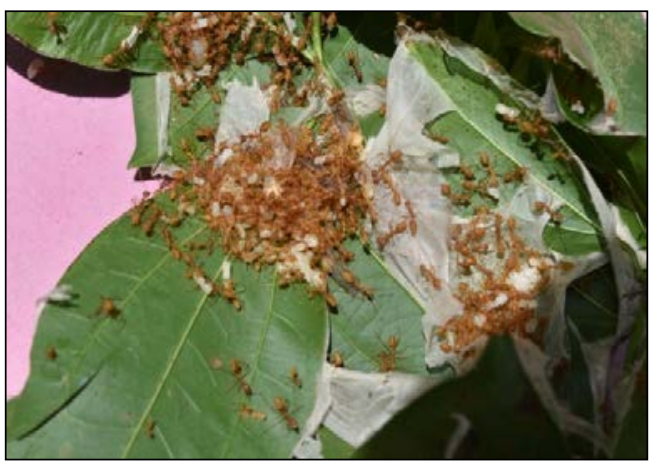

Figure 5. Open nest at the botanical garden of the Vitthalbhai Patel \& Rajratna P. T. Patel Science College, Vallabh Vidya Nagar.



Figure 6. Open nest with queens at the botanical garden of the Vitthalbhai Patel \&Rajratna P. T. Patel Science College, Vallabh Vidya Nagar

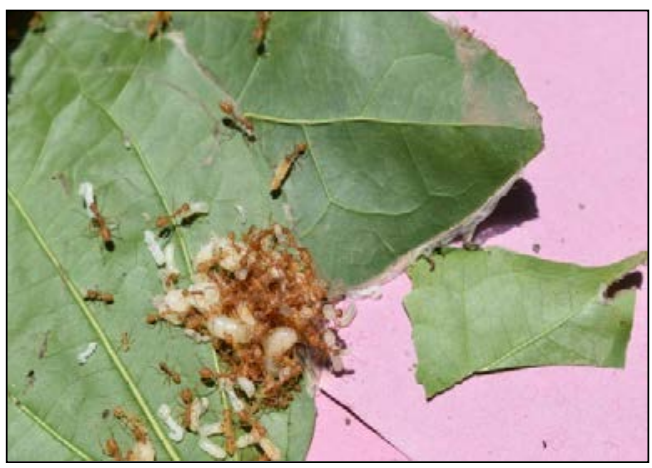

Figure 7. Open nest with larva, minor and major workers at the botanical garden of the Vitthalbhai Patel \& Rajratna P. T. Patel Science College, Vallabh Vidya Nagar.

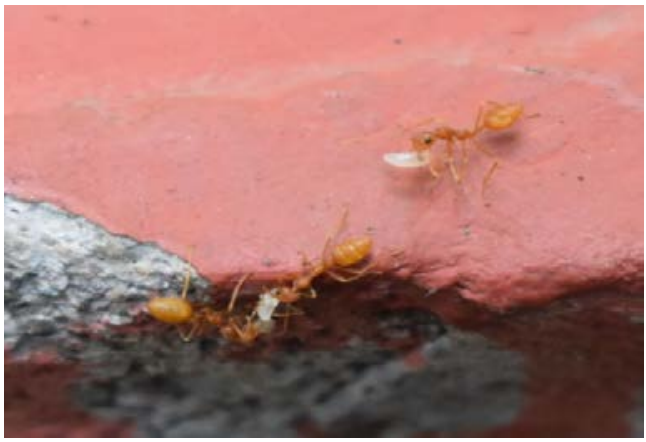

Figure 8. Major worker with larva showing protective behavior at the botanical garden of the Vitthalbhai Patel \& Rajratna P. T. Patel Science College, Vallabh Vidya Nagar.



Figure 9. Ants with Spider showing foraging behavior

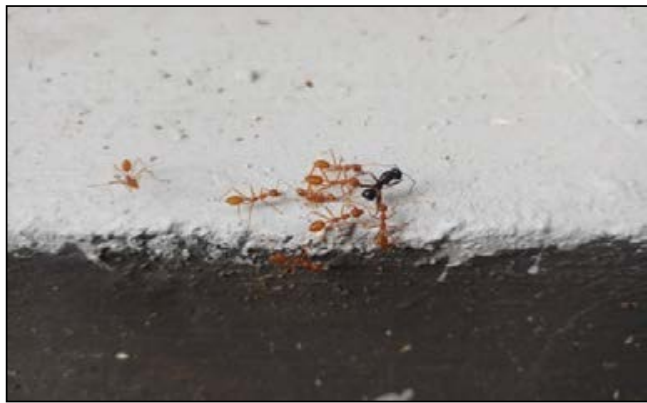

Figure 10. Ants with Carpenter ant showing foraging behavior

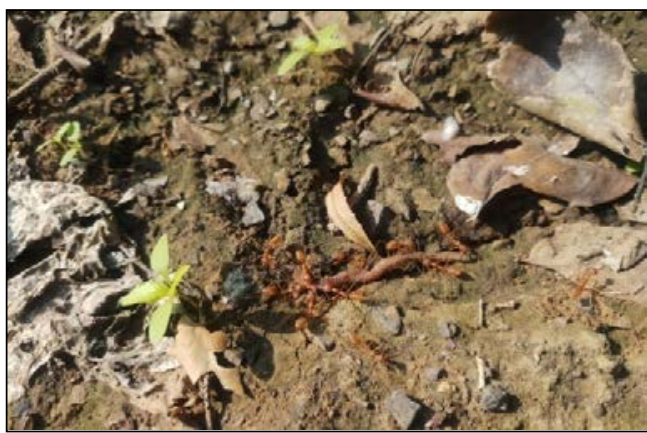

Figure 11. Ants with Earthworm showing foraging behavior

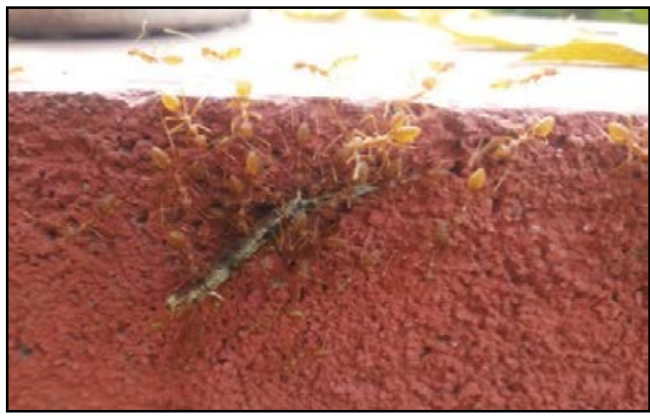

Figure 12. Ants with Caterpillar showing foraging behavior

\subsection{Nesting Behavior}

We have observed four nests of Oecophylla smaragdina, two from the botanical garden of Vitthalbhai Patel \& Rajratna P. T. Patel $\left(22^{\circ} 55.095^{\prime} N, 7^{\circ} 92.694^{\prime}\right.$ E) Science College, Vallabh Vidya Nagar, Gujarat(Fig: 1 and Fig: 2) and two from the botanical garden of Ayurvedic College from A. D. Patel Institute of Technology campus 
$\left(22^{\circ} 31.405^{\prime} \mathrm{N}, 72^{\circ} 55.081^{\prime} \mathrm{E}\right)$, New Vallabh Vidya Nagar, Gujarat (Fig: 3 and Fig: 4). After collecting the nests from both these locations, we dissected it on a clean sheet of paper with utmost care without harming the population (Fig: 5). In Oecophylla species, nest building is a complex task that is achieved by either single ant or by group of worker ants. It was clearly noticeable that the multiple castes within the nest as well as the colony cooperate to construct the nest showing complexity (Fig: 7). When the distance between two leaves is small one or two ants can pull them together while if the distance is large special group of workers forms a long stretch that drag the leaves together to construct a nest. Once they move on in combinatorial manner they initiate to form a large area for their nest. On the contrary, another chief task is to seal the breach between the two edges of leaves. To complete this task, additional workers grasp the larvae of the nest with their mouth and squeeze the larvae to produce more silk that helps to form a close circuit by weaving the leaves for the construction of the walls of nest. These arboreal nests were constructed with the silk produced by larvae which acts as a gluing material. The leaves which are in close proximity are drawn together by the workers showing highly precise teamwork (Fig: 13). Furthermore, when ants build the nest they form different compartments inside the nest where ten to twelve queens are present in nest(Fig: 6). There were two types of larva which are responsible for building the nest through division of labor. The male larvae are smaller than female larva and they have less incentive to help females for weaving the nest (Fig: 7). The main reason behind this is the male larval salivary glands are smaller than females. Moreover, Oecophylla smaragdina shows high rates of characteristics of aggregation during the formation of nest in the colony.

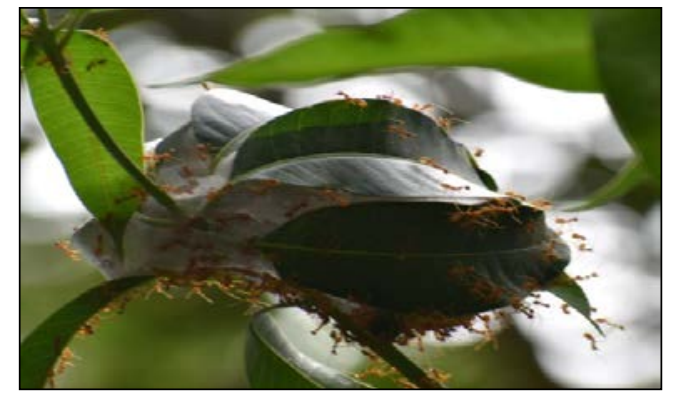

Figure 13. Major workers sealing the edges of leaves

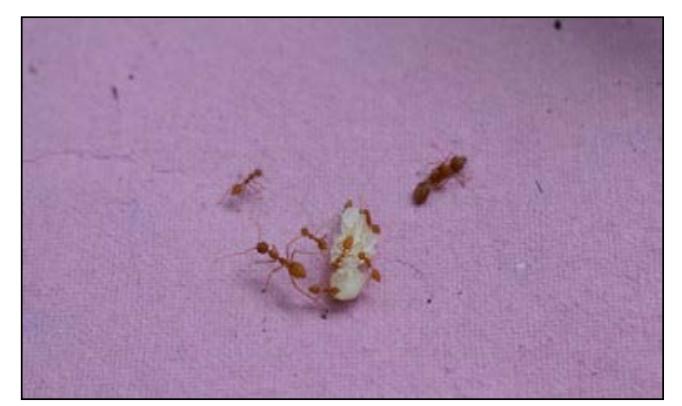

Figure 14. Difference in the size of major and minor worker

\subsection{Protective Behavior towards Colony Mates}

Ants like Oecophylla smaragdina are also responsible for showing protective behavior. This means when they found that there is something wrong within their surrounding area, they try to find a new place to reside. During dissection of the nest it was clearly visible that as soon as a scissors were used to be inserted into nest, the worker ants started to protect their larvae. Later on it was considerably fast and easy to interpret that they always try to hide themselves interiorly rather than moving around in a haphazard manner. In some of the pictures it can be easily visualized that the major worker start to migrate to other places along with holding their larvae in mouth (Fig: 8). After that they commence to stumble on to a new place within the same colony or on a different tree of same habitat to build new nest. The queen from the dissected nest was also trying to locate a new place within the habitat either to mate with the male or to secure themselves to lay eggs once they finish with the courtship by nuptial flight. Though there is difference in the size of major and minor workers they collectively put all the efforts to save the queen and its larva (Fig: 14). Throughout that period of time while separating the nest, the queen though possesses wings but they just marched to another location to find a secured place instead of flying.

\subsection{Foraging Behavior by Foragers}

Foraging is highly mandatory to keep the colony existing and also to provide nourishment to the brood. Till now, work had been exposed by providing special diet to Oecophylla smaragdina (weaver ants) to study foraging behavior. In this study, we did not provided with special diet but instead we observed foraging under natural conditions without disturbing the group of foragers or the colony mates. According to the food preferences we interpreted that these ants more likely include food that have high protein content. In our fields as it was in garden, insects and other invertebrates are found large in number. In one of the photograph (Fig: 9) we have also shown that they are marching with a spider as their food. Sometimes they attack on other species of ants (carpenter ants) as their food (Fig: 10). In another photograph, one can easily see that the group of foragers is carrying an earthworm as their food (Fig: 11) and caterpillar (Fig: 12) as their food towards their nest.

\section{Discussion}

From the above reported study we remarkably noticed that these weaver ants (Oecophylla smaragdina) are having high specificity in their behavioral pattern. A very little research has been done on weaver ants, especially in India. As far as nest building is concerned Oecophylla smaragdina prepares fabulous nest. To prepare their nests all the members of the colony except queen, working hard 
as these nest are arboreal. The workers build the nests collectively by manipulating the larva with the mandibles to weave the nest. The points at which the larvae touch the substrate (the leaf) result in the production of silk by the larva [9]. The nest could be made up of one leaf or multiple leaves depending upon the area required to assemblage their nest. The nest are green and white because of larval silk when they are freshly prepared but once they leave their nest the nest dries up. The reason behind this is yet to be found. Again for nesting there are various factors that actually make it to happen. Factors like temperature, light and humidity can affect the position and size of the nest to be built on a tree. Additionally in our studies we also found that these ants are highly specific about their nest mates. When we dismantled their nests, the ants were grabbing their larva of queen, major and minor workers with their mouth parts to shift them to a new place as a part of protection and possessiveness towards their nest mates. Till now the protection for the colony mates have not been ever studied, so that has been novel to us. Foraging activity is also a main regimen to be completed by the special group of ants. These groups are known as foragers. They are responsible for collecting the food from the external environment other than nest. The queen will feed by the workers who procure their food from the foragers. In one of the species other than this (Oecophylla longinoda) the size of the food particle will have great impact to be foraged by the foragers. Also the type of food is under consideration. Fresh tissues of flesh or meat are preferred more rather than old and dried one[20]. In our study we have observed the foraging activity in natural condition without and food preference. We found that they are highly carnivorous as they were eating insects as wells as annelids like earthworm (small sized). This for the first time we reported it in their natural environment without manipulating. Thus we have interpreted that they shows eusociality, protective and foraging activity positively to sustain their life.

\section{Conclusions}

Though the ants are very aggressive in nature, they however are responsible to show eusociality in terms of nesting, protection and foraging against the enemies for their own colony and nest mates. From the above work, we concluded well that these ants are highly social in diverse terms. Many of the species of ants show raft building, herding and enemy destruction while ants like Oecophylla smaragdina shows highly magnificent arboreal nest building behavior on mango trees (Mangifera indica). Moreover, they are highly season specific and thus they develop their nests during warm temperature when the humidity is extremely high. This type of nest building is a peculiarity of species Oecophylla smaragdina. Additionally, while working with these ants we also observed that when we try to see the nest interior by dissecting it, the workers and the queens are trying to internalize it within the deeper area where the ants have built the compartments. Besides this when the nest is disturbed, the worker ants will clutch the remaining larva individually for saving them and locating a new habitat for the rest of the nest mates. Oecophylla smaragdina along with nest building and protective behavior, also forage in order to provide food to their nest mates. Here, the queen just like honeybees does not go for searching food. The workers (foragers) will go for seeking food for others. Thus the ants Oecophylla smaragdina show nesting, protective and foraging behavior naturally.

\section{Acknowledgements}

We would like to thank Dr. Bhavesh Patel Principal, Vitthalbhai Patel and Rajratna P. T. Patel Science College, Vallabh Vidya Nagar and Charutar Vidya Mandal for their support and permission for the research activities.

\section{REFERENCES}

[1] Antmaps.org: The Global Ant Biodiversity Informatics (GABI) database: Synthesizing data on the geographic distribution of ant species (Hymenoptera: Formicidae)

[2] B. Holldobler, E. 0. Wilson: "The Ants" Springer, Berlin, 1990. 732 . DM 198.-

[3] Carl Anderson, Nigel R. Franks. Teamwork in Animals, Robots, and Humans. Advances in the Study of Behavior, 2003.Theoretical Ecology Series, Volume 4, 2007, Pages $107-138$.

[4] Christian Peeters and Alan N. Andersen. Cooperation between dealate queens during colony foundation in the green tree ant, Oecophylla smaragdina. Psyche: A journal of entomology, Vol. 96 (1989), pp. 39 - 44.

[5] Deborah M. Gordon, Katherine N. Dektar, Noa Pinter-Wollman. Harvester Ant Colony Variation in Foraging Activity and Response to Humidity. PLOS ONE, www.plosone.org, May 2013, Volume 8-Issue 5, e63363.

[6] Ganesh Gathalkar and Avalokiteswar Sen. Foraging and Predatory Activities of Ants http://dx.doi.org/10.5772/intec hopen.78011 (C)

[7] George R. Reinhart, Social organization of ants and humans, Free inquiry in Creative Sociology Volume 8, No.1, May 1980, pp. $100-107$.

[8] Joachim Offenberg, Nguyen Thi Thu Cucand Decha Wiwatwitaya. The effectiveness of weaver ant (Oecophylla smaragdina) biocontrol in Southeast Asian citrus and mango, ASIAN MYRMECOLOGY Volume 5, 2013, pp. 139-149.

[9] Kadambari Devarajan. The Antsy Social Network: Determinants of Nest Structure and Arrangement in Asian Weaver Ants. PLoS ONE 11(6): e0156681. 
doi:10.1371/journal.pone.015668, 2016, pp. 1 - 15 .

[10] Liviu A. Panait and Sean Luke. Article on: Learning Ant Foraging Behaviors. George Mason University, Fairfax, 2004, VA 22030, pp. 1 - 6.

[11] Lokkers, C. Colony dynamics of the green tree ant (Oecophylla smaragdina FAB.) in a seasonal tropical climate. - PhD thesis, 1990. James Cook University of North Queensland, Towns-ville, Queensland, 301 pp.

[12] Marcela Pimid, Abu Hassan Ahmad, Kumara Thevan Krishnan and Joanna Scian. Food Preferences and Foraging Activity of Asian Weaver Ants, Oecophylla smaragdina (Fabricius) (Hymenoptera: Formicidae), Tropical life sciences research, 2019, pp. 167 - 179. DOI: https://doi.org/10.21315/tlsr2019.30.2.12

[13] Martin J. Babu, Shreya M. Ankolekar and K. P. Rajashekhar. Castes of the weaver ant Oecophylla smaragdina (Fabricius) differ in the organization of sensilla on their antennae and mouthparts in Current science, Vol. 101, no. 6, 25 September 2011, pp. 755 - 764.

[14] Paul Van Mele and Nguyen Thi Thu Cue, Ants as friend: Improving tree crops with weaver ants, CAB International, Modern Lithographic (K) Limited Nairobi, Kenya2007.

[15] Philip Newey, Ellen Antje Schlüns and Simon K A Robson. A masterpiece of evolution-Oecophylla weaver ants (Hymenoptera: Formicidae) Article in Myrmecological
News · May 2010, pp. 56 - 71.https://www.researchgate.ne t/publication/228666287.

[16] Philip Newey, Simon K A Robson and Ross H. Crozier Weaver ants Oecophylla smaragdina encounter nasty neighbors rather than dear enemies. Ecological Society of America, Ecology, 91(8), 2010, pp. 2366-2372.

[17] Robin Stuart and Joan Herbers. Nest mates recognition in ants with complex colonies: with-in and between population variation. Behavioral Ecology Vol 11, 2000, No. 6: 676-685.

[18] Sabina Langthasa and RobindraTeron and Ajit Kumar Tamuli, Weaver ants (Oecophylla smaragdina): A multi-utility natural resource in Dima Hasao district, Assam. International Journal of Applied Environmental Sciences, ISSN 0973-6077 Volume 12, No: 4, 2017, pp. 709-715.

[19] Tucker Balch, Zia Khan and Manuela Veloso. Automatically Tracking and Analyzing the Behavior of Live Insect Colonies. School of Computer Science Carnegie Mellon University Pittsburgh, PA 15213, 2001, pp. 1 - 8.

[20] Wilson Nene, Gration M Rwegasira, Maulid Walad Mwatawala, Mogens Gissel Nielsen and Joachim Offenberg. Foraging behavior and Preferences for Alternative Supplementary Feeds by the African Weaver Ant, Oecophylla longinoda Latreille (Hymenoptera, Formicidae) JHR 50: 117-128 (2016) doi: 10.3897/JHR.105.8173 http://jhr.pensoft.net 